Article

\title{
The Improvement of Land Cover Classification by Thermal Remote Sensing
}

\section{Liya Sun ${ }^{1,2, *}$ and Karsten Schulz ${ }^{2}$}

1 Department of Geography, Ludwig Maximilian University of Munich, Munich 80333, Germany

2 Institute for Water Management, Hydrology and Hydraulic Engineering (IWHW), University of Natural Resources and Life Sciences, Vienna 1180, Austria; E-Mail: karsten.schulz@boku.ac.at

* Author to whom correspondence should be addressed; E-Mail: liya.sun@boku.ac.at; Tel.: +43-1-47654-5501; Fax: +43-1-47654-5549.

Academic Editors: Ruiliang Pu and Prasad S. Thenkabail

Received: 1 May 2015 / Accepted: 16 June 2015 / Published: 26 June 2015

\begin{abstract}
Land cover classification has been widely investigated in remote sensing for agricultural, ecological and hydrological applications. Landsat images with multispectral bands are commonly used to study the numerous classification methods in order to improve the classification accuracy. Thermal remote sensing provides valuable information to investigate the effectiveness of the thermal bands in extracting land cover patterns. $k$-NN and Random Forest algorithms were applied to both the single Landsat 8 image and the time series Landsat 4/5 images for the Attert catchment in the Grand Duchy of Luxembourg, trained and validated by the ground-truth reference data considering the three level classification scheme from COoRdination of INformation on the Environment (CORINE) using the 10-fold cross validation method. The accuracy assessment showed that compared to the visible and near infrared (VIS/NIR) bands, the time series of thermal images alone can produce comparatively reliable land cover maps with the best overall accuracy of $98.7 \%$ to $99.1 \%$ for Level 1 classification and $93.9 \%$ to $96.3 \%$ for the Level 2 classification. In addition, the combination with the thermal band improves the overall accuracy by 5\% and $6 \%$ for the single Landsat 8 image in Level 2 and Level 3 category and provides the best classified results with all seven bands for the time series of Landsat TM images.
\end{abstract}

Keywords: thermal remote sensing; land cover classification; Landsat image; $k$-NN; random forest; cross validation 


\section{Introduction}

Land cover is defined as the observed biophysical state of the earth's surface, and is largely described by the presence or absence of various vegetation types [1]. In contrast, land use normally refers to the arrangements, activities and inputs people engage in a certain land cover type to produce, change or maintain it [2]. As previous studies reported, land cover information is a fundamental variable for many hydrological and climate studies. Land cover characteristics have close links to the human and physical environments, also govern and affect many environmental variables [3], including surface roughness, albedo, moisture availability, mechanisms for runoff generation [4], and water quality [5]. Therefore, accurate land-cover mapping becomes essential for modeling and understanding these biogeophysical properties of the land surfaces.

Remote sensing provides an effective way to depict land cover as it produces a map-like representation of the Earth's surface that is spatially continuous and highly consistent, as well as available at a range of spatial and temporal scales [1]. The Landsat satellites have monitored the Earth's terrestrial surfaces for about 40 years [6], from which the long, consistent and free record allows scientists to study the current and also the past land surface patterns. Because of that, Landsat data are widely applied in land cover classification and monitoring on a regional or global scale. Numerous studies have proved the usefulness of Landsat imagery in agricultural land cover classification [7], forest dynamics monitoring [8], urban land use classification [9], other land cover dynamics or land use land cover (LULC) change detection $[6,10,11]$. Other satellite products such as the Advanced Spaceborne Thermal Emission and Reflection Radiometer (ASTER) sensor imagery have also been widely used for regional scale land cover classification [12-14] or land cover change detection $[15,16]$.

In most cases, the LULC classification is based on the multispectral characteristics and/or the multi-temporal biological properties of the Earth's surface. In previous studies, numerous efforts have been made to improve the classification accuracy by constructing different spectral features, developing new methods, or integrating multi-source data for the single or time series of images. Lunetta and Balogh [17], for example, evaluated the identification of wetlands with the bands 2 to 5 of the single-date and multi-temporal Landsat 5 images. The overall accuracy (OA) was $69 \%$ of the single-date image compared to $88 \%$ from the two-date images with a significant increase in the Kappa test statistics. Murai and Omatu [18] proposed a pattern classification method which integrates the advantages of both the neural network and knowledge-based system. The single Landsat 5 TM image with the bands 3 to 5 was used and they found that the misclassification can be revised more easily because of introducing the geographical knowledge into the system. Maxwell et al. [19] introduced an automated approach to classify four land cover types using only the bands 2 and 4 from Landsat MSS with $92.2 \%$ OA.

Langley et al. [20] compared the single-date imagery and multi-temporal images for land cover classification with the bands 3 to 5 of TM image. They concluded that the multi-temporal images have improved the accuracies of some landscapes but the single-date image may provide a reliable vegetation cover map in semi-arid environments. Saadat et al. [21] utilized two single-date Landsat ETM+ image without the thermal bands for LULC classification in Iran with OA of 95\% and $82 \%$ respectively for the late summer image and the spring image. He recommended that when the satellite 
image is limited the late summer image would be most suitable for the LULC classification. Guerschman et al. [22] also suggested that, if possible, three images (spring, early summer, late summer) be used in the identification of agricultural types. Yuan et al. [23] used multi-temporal TM images from 1986 to 2002 to monitor the LULC dynamic with the average OA of $94 \%$ and proved the potential of multi-temporal Landsat data for accurate and economic land cover change analysis. Besides the different band combinations, the normalized difference vegetation index is also commonly used for the LULC change detection with the multi-temporal images [6,24-27]. For both single-date image and multi-temporal images, several studies focus on the algorithm development such as nearest neighbor $(\mathrm{NN})$ [28], modified $\mathrm{NN}$ [7,29], random forest classifier [30-32], and rule-based classification $[33,34]$, which all provide accurate land cover classification maps.

However, surprisingly, the thermal information provided by many of the satellite platforms has rarely been used for land cover classification [35]. Thermal remote sensing allows for the continuous representation of land surface temperature [36], which is widely used for the monitoring of urban climate [37], the modeling of the hydrological cycle [38], vegetation monitoring [39] and mapping land surface energy and water vapor fluxes [40]. Although the spatial resolution of the thermal band is coarser when compared to the visible bands of the same satellite, the thermal information may contain valuable information related to the spatial variations of land surface and therefore vegetation properties $[41,42]$, which has so far not been explored to its full extent.

The objective of this study therefore is to investigate the value and effectiveness of the thermal remote sensing data for improving land cover classification. The test region is the Attert catchment in Luxemburg/Belgium providing a landscape with a variety of land cover types, mainly including forest, agriculture land, pasture and residential area. Based on the land cover change maps from 1990 to 2006 provided by CORINE and the change maps from 1972 to 1990 and 2006 to 2011 from CAOS project (not present in this paper), the land cover changes in quite small extent in 5 to 8 years especially in the early 1990s. In this study, the variation among different land covers is ignored and the land cover types of Level 1 and Level 2 are assumed to be constant during the periods from 1984 to 1990 and 2006 to 2011. Two of the most often and successfully applied standard methods, the $k$-NN [43], as well as the Random Forest method [44], will be applied to Landsat 4/5 and Landsat 8 images. Three groups of the single-date Landsat 8 images with different visible and thermal bands combinations will be classified into three levels of land use land cover categories, in order to evaluate the effectiveness of the thermal band in single image classification. The combination of band 3 and band 4, principal components, 6 bands combination without the thermal band, the thermal band and a 7 bands combination including the thermal band from time series Landsat $4 / 5$ images listed in two groups will be classified into two levels for comparison and performance analysis. Ten-fold cross validation will be applied for the accuracy assessment with the overall accuracy.

\section{Data Source}

\subsection{Study Area}

The study area of Attert catchment as the main test site of German DFG research project CAOS ("Catchments as Organized Systems") is located in the Midwestern part of the Grand Duchy of 
Luxembourg and partially in Belgium (Figure 1). The catchment covers a total area of $288 \mathrm{~km}^{2}$. The main land cover types consist of dense deciduous and coniferous forests, spacious pasture and croplands, and a sparse residential area. According to the CORINE land cover map in 2006, the agricultural area takes up $65 \%$ and forest accounts for about $30 \%$ of the catchment. The elevation of the Attert basin ranges from $238 \mathrm{~m}$ to $539 \mathrm{~m}$. With a temperate climate, the mean monthly temperatures reaches a maximum of about $18{ }^{\circ} \mathrm{C}$ in July and a minimum of $0{ }^{\circ} \mathrm{C}$ in January. The high summer evapotranspiration from July to September and high flows from December to February is characterized by the mean annual precipitation of $850 \mathrm{~mm}$ and the mean annual actual evapotranspiration of $570 \mathrm{~mm}$ (1971-2000).

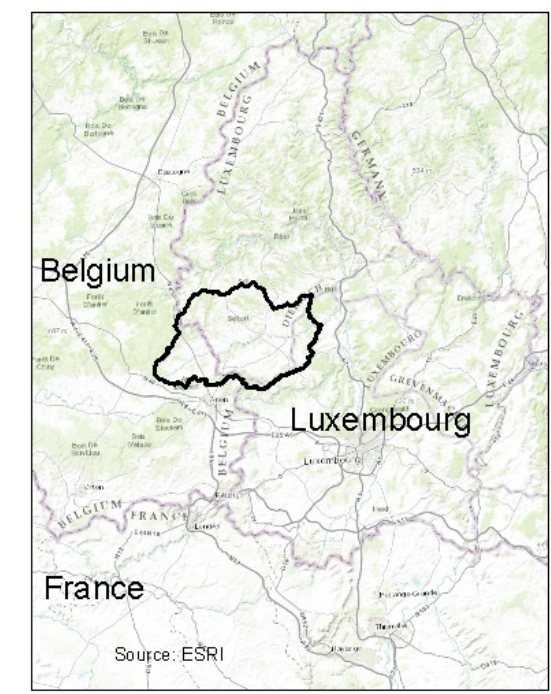

$0510 \quad 20 \quad 30 \quad 40$

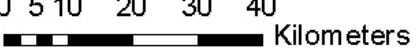

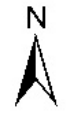

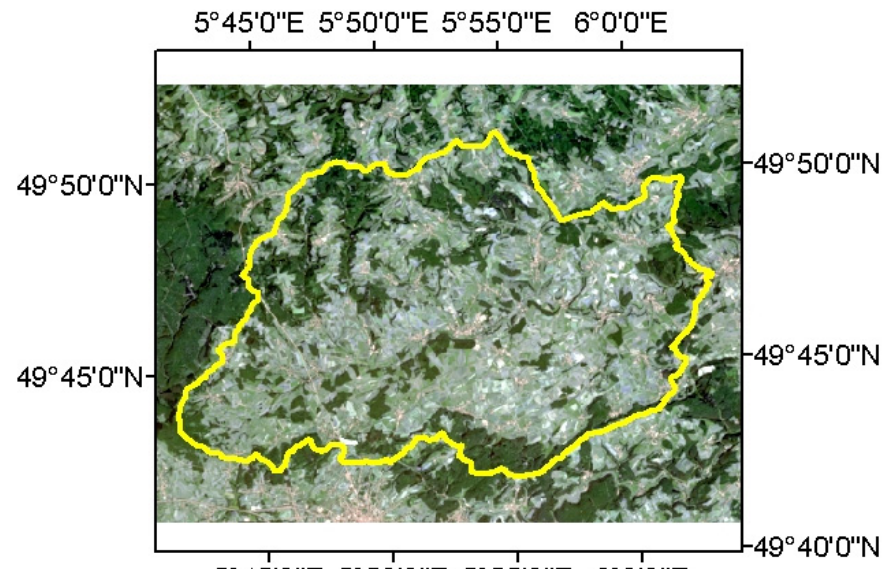

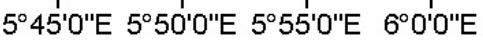

$\begin{array}{llllll}0 & 2 & 4 & 8 & 12 & 16\end{array}$

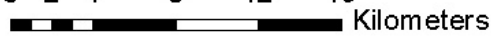

Figure 1. Illustration of the Attert catchment location crossing Luxembourg and Belgium in the ESRI map layout (left) and zoomed study area in yellow outline (right) with a Landsat 8 image of July, 2013 in RGB combination of band 3, band 2 and band 1.

\subsection{Satellite Data}

The Landsat Thematic Mapper (TM) sensor was carried onboard of Landsat 4 and 5 from July 1982 to May 2012 with a 16-day repeat cycle, and began decommissioning in January 2013. TM images consist of seven spectral bands (Table 1) with a spatial resolution of $30 \mathrm{~m}$ for Bands 1 to 5 and 7 . The spatial resolution for Band 6 (thermal infrared) is $120 \mathrm{~m}$, but is resampled to $30 \mathrm{~m}$ pixels in the provided L1T products after 25 February 2010. A total of 13 cloud-free TM images between 1982 and 2012 were collected for the Attert catchment (path 197, row 25). The newly launched (on 11 February 2013) Landsat 8 Operational Land Imager (OLI) and Thermal Infrared Sensor (TIRS) provide nine spectral bands and two thermal bands as listed in Table 1. All spectral bands are collected at $30 \mathrm{~m}$, except for the thermal bands that are acquired at $100 \mathrm{~m}$ resolution and resampled to $30 \mathrm{~m}$ in the delivered product and the panchromatic band 8 providing $15 \mathrm{~m}$ data. One cloud-free Landsat 8 image was acquired for 21 July 2013 (at the same time the ground-truth field campaign was conducted). The 
Landsat images available for this study have been divided into three groups (see Table 2): Group 1 (TS1) and Group 2 each contain time series of images covering spring, summer and autumn (TS1 covers the Landsat 4/5 images from 1984 to 1990 and TS2 includes the Landsat 5 images from 2003 to 2011). Both groups were used to investigate the land cover classification performance when based on time series of images. The third group (S1) with only one Landsat 8 image from 21 July 2013 was tested to explore the effectiveness of single image land cover classification based on thermal data.

Table 1. Spectral characteristics of the 7 bands from Landsat $4 / 5 \mathrm{TM}$ image and the 11 bands from Landsat 8 image.

\begin{tabular}{ccc}
\hline Bands & Landsat 4/5 Wavelength (Micrometers) & Landsat 8 Wavelength (Micrometers) \\
\hline Band 1 & $0.45-0.52$ & $0.43-0.45$ (Coastal aerosol) \\
Band 2 & $0.52-0.60$ & $0.45-0.51$ (Blue) \\
Band 3 & $0.63-0.69$ & $0.53-0.59$ (Green) \\
Band 4 & $0.76-0.90$ & $0.64-0.67$ (Red) \\
Band 5 & $1.55-1.75$ & $0.85-0.88$ (Near Infrared (NIR)) \\
Band 6 & $10.40-12.50$ & $1.57-1.65$ (SWIR 1) \\
Band 7 & $2.08-2.35$ & $2.11-2.29$ (SWIR 2) \\
Band 8 & & $0.50-0.68$ (Panchromatic) \\
Band 9 & & $1.36-1.38$ (Cirrus) \\
Band 10 & & $10.60-11.19$ (Thermal Infrared (TIRS) 1) \\
Band 11 & & $11.50-12.51$ (Thermal Infrared (TIRS) 2) \\
\hline
\end{tabular}

Table 2. All Landsat images used for the land cover classification including two groups (TS1 and TS2) of time series of Landsat 4/5 images from 1984 to 2011 and the single-date Landsat 8 image (S1) in July 2013.

\begin{tabular}{ccccc}
\hline Group & Date & Day of Year & Sensor & Season \\
\hline \multirow{6}{*}{ TS1 } & $1984-08-22$ & 235 & Landsat 5 & Summer \\
& $1985-08-09$ & 221 & Landsat 5 & Summer \\
& $1987-10-02$ & 275 & Landsat 5 & Fall \\
& $1988-04-11$ & 102 & Landsat 5 & Spring \\
& $1988-05-13$ & 134 & Landsat 5 & Spring \\
& $1989-05-16$ & 136 & Landsat 5 & Spring \\
& $1990-07-14$ & 195 & Landsat 4 & Summer \\
\hline \multirow{3}{*}{ TS2 } & $2003-08-11$ & 223 & Landsat 5 & Summer \\
& $2006-07-02$ & 183 & Landsat 5 & Summer \\
& $2006-07-18$ & 199 & Landsat 5 & Summer \\
& $2009-06-24$ & 175 & Landsat 5 & Spring \\
& $2011-04-11$ & 101 & Landsat 5 & Spring \\
\hline S1 & $2011-09-02$ & 245 & Landsat 5 & Fall \\
\hline
\end{tabular}

\subsection{Land Cover Classification Scheme and Reference Data}

In this study, the three-level land cover classification system of CORINE established by the European Union [45] was utilized to represent the major land cover types (Table 3). Due to the lack of 
in situ ground truth data of the agricultural area and crop variations in the same area for the images in the different years, only the Level 1 (4 land cover classes) and Level 2 ( 7 land cover classes) were considered for the time series classification of Landsat images. While for the single image classification in 2013, combined with the ground truth data, all the three levels were classified and tested for the study area.

Table 3. Land use and land cover categories for the three-level classification scheme including the 4 classes of Level 1,7 classes of Level 2, 14 classes of Level 3 and the brief description of the Level 3 classes.

\begin{tabular}{|c|c|c|c|}
\hline Level 1 & Level 2 & Level 3 & Description of Level 3 \\
\hline \multirow{9}{*}{ Agricultural land } & Bare soil & Bare soil & Fallow agricultural land or harvested land \\
\hline & \multirow{6}{*}{ Cropland } & Barley & \\
\hline & & Corn & Arable land for different crops, \\
\hline & & Wheat & including the non-irrigated arable \\
\hline & & Triticale & and permanently irrigated land, \\
\hline & & Rapeseeds & heterogeneous agricultural areas \\
\hline & & Oat and other crops & \\
\hline & \multirow{2}{*}{ Grassland } & Intensive Grassland & Dense grass cover, includes areas with hedges \\
\hline & & Extensive grassland & Sparse grass cover, includes areas with hedges \\
\hline Artificial land & Artificial land & Artificial land & $\begin{array}{l}\text { Urban fabric, industrial, commercial and } \\
\text { transport units, mine, dump and construction sites, } \\
\text { artificial non-agricultural vegetated areas }\end{array}$ \\
\hline \multirow{3}{*}{ Forest } & Deciduous Forest & Deciduous Forest & $\begin{array}{l}\text { Broad-leaved forest species, predominated by } \\
\text { beech, oak, including shrub and bush understories }\end{array}$ \\
\hline & Coniferous Forest & Coniferous Forest & $\begin{array}{l}\text { Coniferous forest species, predominated } \\
\text { by pine, larch, including shrub and bush understories }\end{array}$ \\
\hline & Mixed Forest & Mixed Forest & $\begin{array}{c}\text { Mixed broad-leaved and coniferous forest, neither species } \\
\text { predominate, including shrub and bush understories }\end{array}$ \\
\hline Water bodies & Water bodies & Water bodies & Water courses and water bodies \\
\hline
\end{tabular}

Training and validating samples were collected from the ground truth data and the reference maps (Figure 2). Firstly, the available historical land cover maps were collected including the finer land cover maps in 2007 provided by the collaborators in the CAOS project, CORINE land cover datasets of 1990, 2000 and 2006. Based on these reference maps and visual interpretation, areas of interest were created for the Level 1 and Level 2 category (the right-hand image in Figure 2). Secondly, the various agricultural lands (550 sites) in Level 3 were labelled through the fieldwork campaign conducted in the Attert catchment from July 8 to 13 July 2013 (the left-hand image in Figure 2). For the single Landsat 8 image, samples for all the three categories were used, whereas due to the impossibility of gaining historical ground truth data, only samples for the Level 1 and Level 2 categories were taken into account. The sample screening was performed for each land cover type in the ERDAS software and only the pure pixels of the relatively larger site were kept. The principle is to obtain the evenly distributed samples over the catchment and to keep the size as similar as possible for both the single-date Landsat 8 image and the two time series of images. 

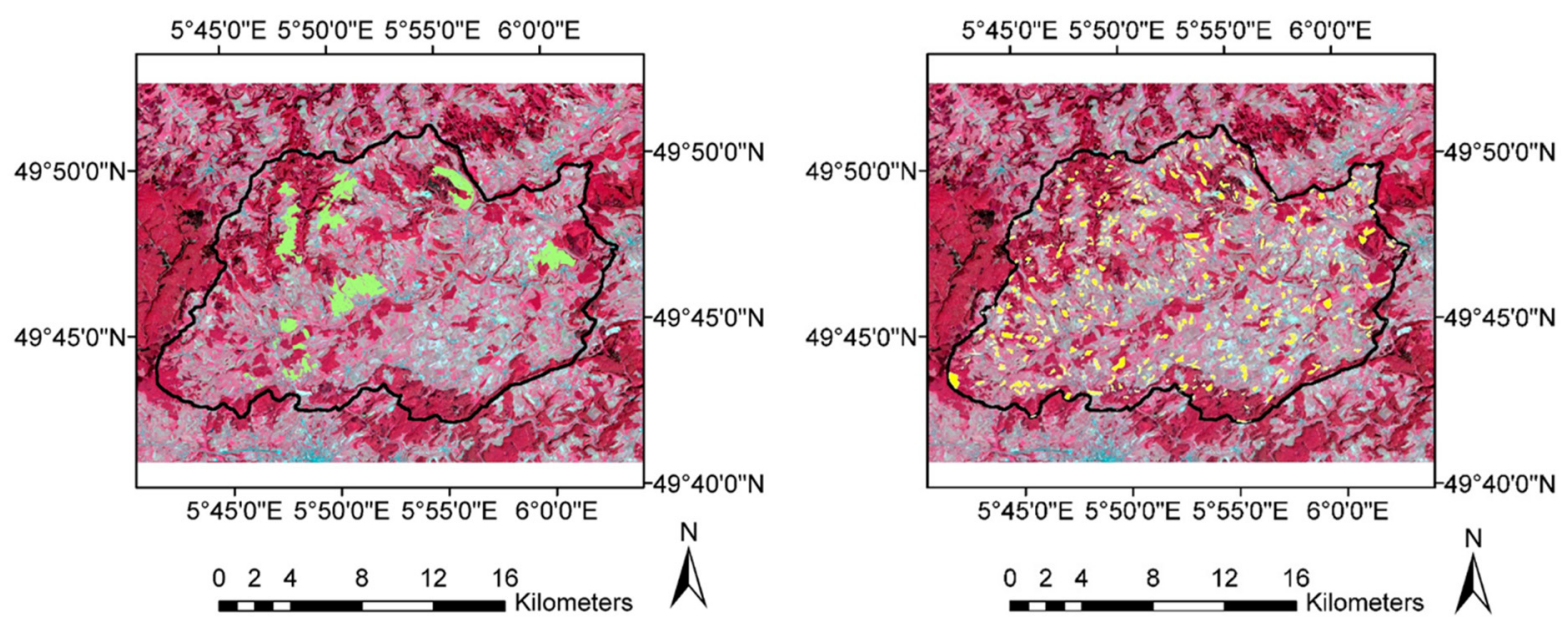

Figure 2. The agricultural ground truth area labelled in green during the field campaign in July 2013 (left) and all the training and validating pixels in yellow for the 7 classes of the Level 2 category based on the historical land cover maps of 2007 (right); the background image of Attert Catchment (outlined in black) is the composite Landsat 8 image of July 2013 in RGB combination of band 4, band 3 and band 2.

The training set size has a great impact on the classification accuracy and appropriate training samples are prerequisites for a successful classification [46,47]. Following the recommendations of Foody [32], van Genderen [45] and Congalton [46], the size of the training set should not be fewer than 10-30 observations per spectral band and per class. In this paper, the size of the samples for Level 1 and Level 2 categories was set greater than 300 pixels. However, only 40 pixels for the water bodies were selected in this catchment because the river courses are normally too small to be distinguished in the Landsat image.

\section{Classification Schemes}

\subsection{Preprocessing}

As reported by Song et al. [48], atmospheric correction of images might not be necessary in case only a single image is used for the classification procedure. However, when multi-temporal or multi-sensor data are used, atmospheric correction is mandatory [49]. Existing studies have tested the importance of different procedures for obtaining the stable and accurate images [50]. Thirteen images used for the land cover classification were corrected by the MODTRAN 4 algorithm [51] embedded in the ATCOR3 module [52] in ERDAS software [53] to remove atmospheric and topographic effects within the resampled $30 \mathrm{~m}$ ASTER GDEM product of METI and NASA [54]. All the corrected images were normally rescaled to the 8-bit raster images by the scale factor 4 for both the reflectance and temperature data, i.e. a digital number value of 20 from the temperature image corresponds to a ground temperature of $5{ }^{\circ} \mathrm{C}$.

For the evaluation of the land cover classification based on the single Landsat 8 image (from 21 July 2013), three variants of spectral band combinations were considered: (i) only the bands $2-5$ from Landsat 8 (Bands4); (ii) bands 2-5 plus the 2 thermal bands 10 and 11 (Bands6T); and (iii) all bands except the panchromatic band (Bands10T). 


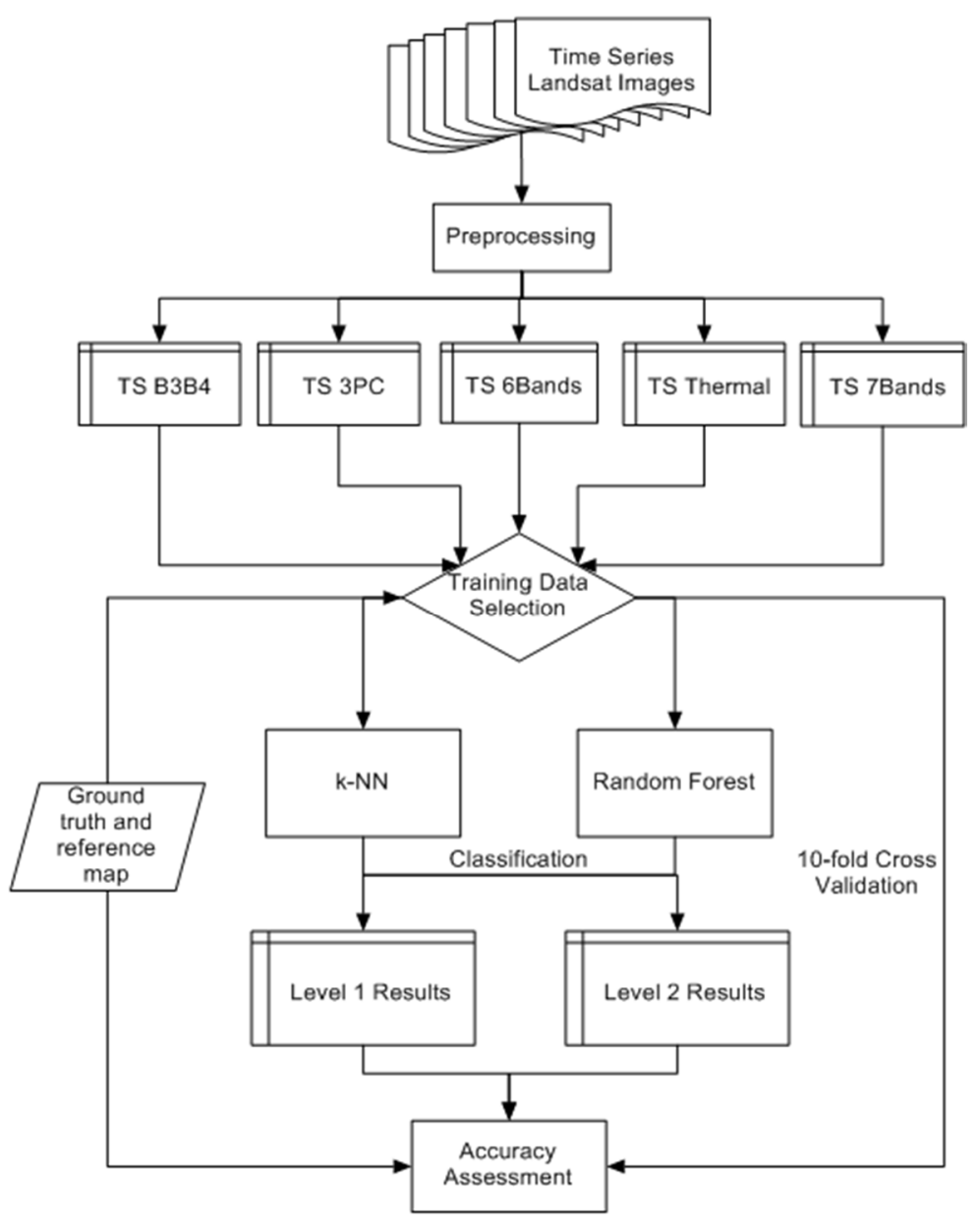

Figure 3. Flowchart of the land cover classification and accuracy assessment process: the time series images were derived from the Landsat 4/5 TM images by preprocessing including: the Band 3 and Band 4 combination (TS B3B4), first three principal components (TS 3PC) of the VIS/NIR bands from TM images, six bands combination except the thermal band (TS 6Bands), the thermal band (TS Thermal) and all the bands combination (TS 7Bands); then based on the ground truth and reference maps training data were selected and used for the k-nearest neighbor and Random Forest algorithms for Level 1 and Level 2 classification; 10-fold cross validation was applied to the both classification methods and then calculated for the accuracy statistics.

For the assessment of the land cover classification based on time series of images (Groups TS1 and TS2, Table 2), five variants of time series were classified and compared. The five variants include time series of the combinations of band 3 and band 4 of Landsat TM images (B3B4), time series of three (PC3) principal components of all the VIS/NIR bands in the TM image, time series of 6 bands except the thermal band ( 6 bands), time series of only the single thermal bands and time series of all 7 bands from the TM images. Bands 3 and 4 of the Landsat TM image refer to the red and near infrared spectrum, of which the combination (e.g. as NDVI) is useful for distinguishing the vegetation, soil, water and land interface. Principal Component Analysis (PCA) was applied to the atmospheric corrected images with 6 bands (excluding the thermal band 6) for dimension reduction. The effectiveness of PCA for the identification of land cover changes has been reported in previous studies $[55,56]$. The three components of the 6 Landsat/TM bands are mainly related to the information 
of the land cover and land use, which explains approximately $98 \%$ of the data variability of all bands. Figure 3 shows the general classification procedure of all the time series Landsat images.

\subsection{Classification Algorithms}

In the field of land-cover classification based on satellite images, numerous machine learning methods are available and have been investigated and reviewed [49,57]. Since the general intercomparison of classification methods was not the focus of this study, experience from previous investigations was used [7,29], and two widely applied methods, the simplest $k$-NN and the more complex Random Forest algorithms were chosen for the land-cover classification given their good performance.

The $k$-NN method is one of the particularly simple classifiers in the concept, which is easy to apply but can be time consuming [58]. Given an object, it examines the training samples in the multispectral feature space and chooses the closest class among the pre-specified number $k$ of nearest neighbors. $k$ is an integer value specified by the user and is highly data-dependent. In general, a larger $k$ suppresses the effects of noise, but makes the classification boundaries less distinct. Normally, $k$-NN needs $a$ priori definition of a metric in the predictor space [29]. There are several studies focusing on finding a reasonable distance to improve the performance of the classification algorithm [7,28], such as the Manhattan distance, Euclidean distance, Chebychev distance, the similarity measures or the Modified Nearest Neighbor which searched for a metric in a lower dimensional space for separating a given class [29]. Here, based on the previous study [7,28] and comparison of the classification performance with different $k$ values and metrics, the optimal number of nearest neighbors is defined as 5 and the distance metric is determined by the standard Euclidean metric.

Another ensemble learning algorithm called Random Forest (RF) is also applied in this study. RF is an ensemble of classification trees and each tree contributes with a single vote for the assignment of the most frequent class to the input data [44]. Breiman [44] introduced RF by using bagging or bootstrap aggregating with a random subset of input features in the division of every node to make the trees grow from different training data subsets. The RF algorithm can handle high dimensional data and uses a large number of trees in the ensemble without variable deletion and estimates the importance of variables in the classification [59]. The RF method has increasingly been applied in the land-cover classification given its higher accuracy and more robust capability to noise and outliners than other machine learning algorithms [30,34].

\subsection{Validation and Accuracy Assessment}

The $k$-fold cross validation, also called rotation estimation [60], is a model validation method for estimating generalization error. In $k$-fold cross-validation, the training set is split into $k$ smaller sets and the classification model is trained using the $k-1$ of the folds as training data, then the resulting model is validated on the remaining part of the data. The accuracy of cross-validation is the average of value in the loop. In this study, 10-fold cross validation was performed with the samples obtained in the Section 2.3. The water body category was not considered in the accuracy assessment due to its small proportion based on the recommendation of the minimum of 50 samples for each category validation by Congalton [61].

Error metrics were calculated to assess the classification accuracy, from which the OA, user's accuracy (UA) and producer's accuracy (PA) were derived [62]. The OA present in this paper is the 
averaged value from 10-fold validation for each $k$-NN and Random Forest classification. User's accuracy refers to the fraction of correctly classified pixels with regard to all pixels classified as this class in the classified image and is also known as the reliability or commission error. Producer's accuracy means the fraction of correctly classified pixels with regard to all pixels of that ground truth class and can also be referred to the accuracy or omission error.

\section{Results and Discussion}

\subsection{Classification Based on A Single Image (S1)}

The land cover classification based on a single image was carried out with the Landsat 8 image from 21 July 2013. As detailed in Section 3.1, three variants with different bands combination were considered and classified into the three land cover levels using the $k$-NN and Random Forest algorithm. The classification results and the accuracy statistics are summarized in Figure 4 and Tables 4 and 5 . Figure 3b,d illustrates the land cover maps with the best OA among all the variants for each category. The consistent patterns can be visually observed in the forest and artificial areas, meanwhile the road in the west part of the catchment is clearly distinguished. For level 2 and level 3, the agricultural areas were classified in more detail based on the ground truth data. The major cropland and grassland areas have been well recognized but misclassification still exist especially between the different crops in Figure $3 \mathrm{~d}$ with the low accuracy data in Table 5.
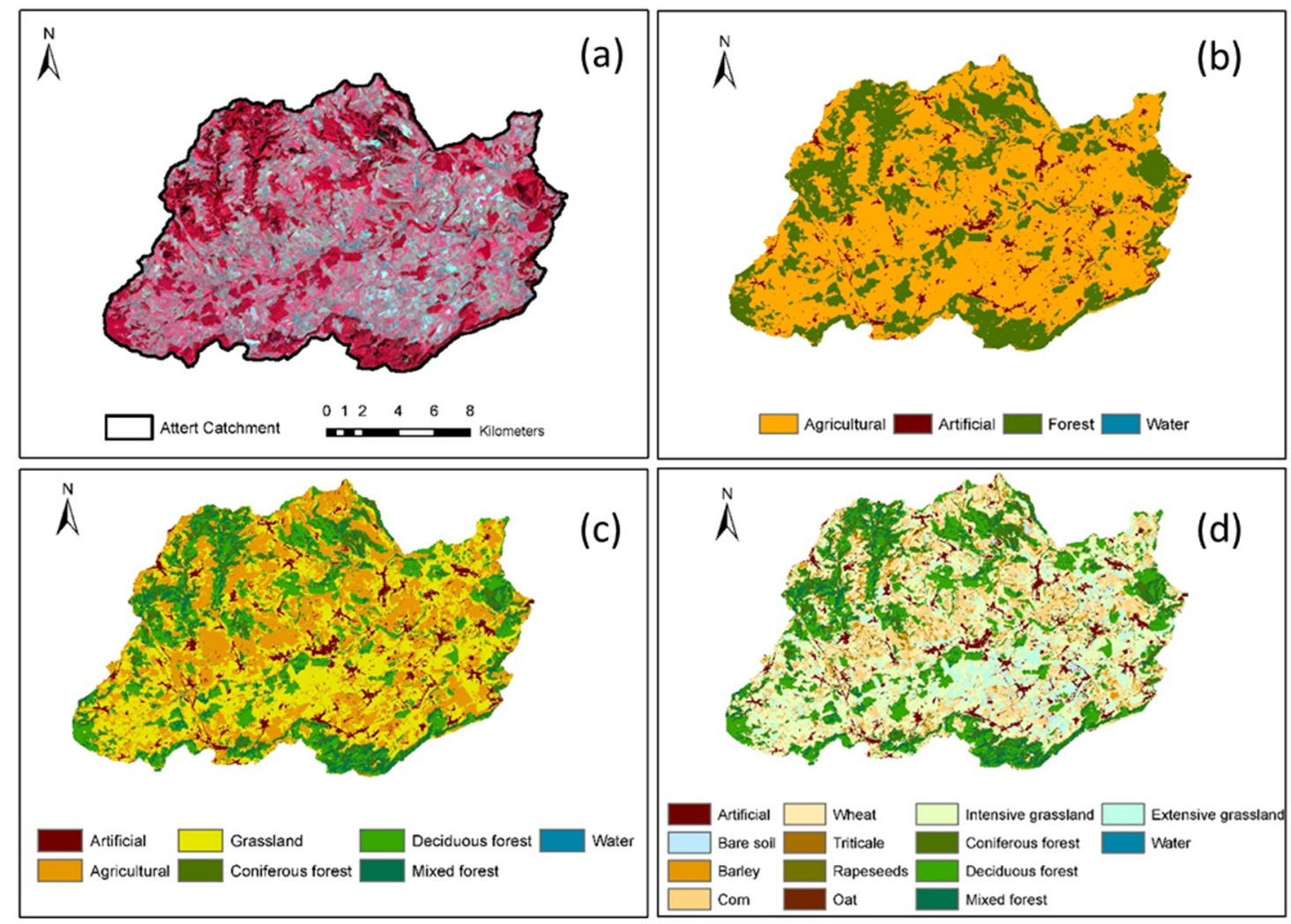

Figure 4. Four land cover maps from Landsat 8 of July 2013: (a) False color composite image in RGB combination of bands 5, 4, 3; (b) Level 1 classification image with 4 classes by k-NN based on the 10 bands combination of the Landsat image; (c,d) Level 2 and Level 3 classification images with 7 and 14 classes by Random Forest based on the 10 bands combination. 
It is clear that the variant Bands10T always achieved the best OA by making use of the available maximum spectral information with 10 bands (Table 4). The high overall accuracies around $98 \%$ for the Level 1 classification indicates that the Bands4 variant has sufficient information to classify the Level 1 category. The classification accuracy drops down strongly with the $80.7 \%$ OA value for Level 3 category, which is much lower than the commonly recommended $85 \%$ target for planning and management purposes [63]. However, it is worth noting that the additional information from the short wave infrared and the thermal spectrum provide more information and better accuracy especially for the Level 2 and Level 3 classification, which improve the OA of Bands $10 \mathrm{~T}$ about 5\% to 8\% for the Level 2 category and 6\% to 12\% for the Level 3 category than the Bands6T and Bands 4 .

Table 4. The mean value calculated by 10 -fold cross validation method for the OA of the three images from Landsat 8 in 2013 with different band combination classified by k-NN and Random Forest: Bands4 represents the image with bands 2 to 5; Bands6T represents the image with bands 2 to 5 and the thermal bands 10 and 11; Bands10T indicates the image with all the 10 bands from Landsat 8 except the panchromatic band; k-NN5 and RF represents the nearest neighbor method with $\mathrm{k}=5$ and Random Forest, respectively.

\begin{tabular}{ccccccc}
\hline & \multicolumn{2}{c}{ Level 1 (\%) } & \multicolumn{2}{c}{ Level 2 (\%) } & \multicolumn{2}{c}{ Level 3 (\%) } \\
\hline Image classification accuracy in 2013 & $k$-NN5 & RF & $k$-NN5 & RF & $k$-NN5 & RF \\
Bands4 OA & 97.6 & 97.6 & 83.9 & 84.7 & 68.7 & 69.9 \\
Bands6T OA & 98.1 & 98.1 & 87.0 & 87.9 & 74.1 & 74.7 \\
Bands10T OA & 98.3 & 98.2 & 91.9 & 92.3 & 79.6 & 80.7 \\
\hline
\end{tabular}

Table 5. The best classification accuracy statistics from the 10 -fold validation by Random Forest chosen for the data analysis of the single Landsat 8 image with 10 bands combination in 2013. PA refers to the Producer's accuracy, UA refers to the User's accuracy, -- represents no validation pixel available.

\begin{tabular}{|c|c|c|c|c|c|c|c|c|}
\hline Level 1 & PA & UA & Level 2 & PA & UA & Level 3 & PA & UA \\
\hline Agriculture & $99.3 \%$ & $98.7 \%$ & Artificial & $94.2 \%$ & $94.3 \%$ & Artificial & $89.1 \%$ & $91.8 \%$ \\
\hline Artificial & $89.4 \%$ & $93.1 \%$ & Cropland & $91.8 \%$ & $92.0 \%$ & Bare soil & $80.4 \%$ & $86.5 \%$ \\
\hline Forest & $98.8 \%$ & $99.3 \%$ & Grassland & $92.5 \%$ & $91.9 \%$ & Barley & $56.7 \%$ & $59.7 \%$ \\
\hline \multirow[t]{2}{*}{ Water } & -- & -- & Conifer & $98.8 \%$ & $94.6 \%$ & Corn & $72.3 \%$ & $64.9 \%$ \\
\hline & & & Deciduous & $97.3 \%$ & $95.5 \%$ & Wheat & $62.7 \%$ & $60.2 \%$ \\
\hline \multirow[t]{10}{*}{$\mathrm{OA}$} & $98.7 \%$ & & Mixed forest & $79.5 \%$ & $92.1 \%$ & Triticale & $30.4 \%$ & $47.1 \%$ \\
\hline & & & Water & -- & -- & Rapeseeds & $47.8 \%$ & $66 \%$ \\
\hline & & & & & & Oat & $48.4 \%$ & $68.2 \%$ \\
\hline & & & $\mathrm{OA}$ & $92.7 \%$ & & Intensive Grassland & $93.1 \%$ & $90.7 \%$ \\
\hline & & & & & & Conifer & $99.0 \%$ & $98.1 \%$ \\
\hline & & & & & & Deciduous & $97.9 \%$ & $94.9 \%$ \\
\hline & & & & & & Mixed forest & $81.9 \%$ & $92.6 \%$ \\
\hline & & & & & & Extensive grassland & $88.2 \%$ & $90.9 \%$ \\
\hline & & & & & & Water & -- & -- \\
\hline & & & & & & $\mathrm{OA}$ & $81.2 \%$ & \\
\hline
\end{tabular}


Table 6. Confusion matrix for the Level 3 category of single Landsat 8 image in July 2013 with 10 bands combination. The column indicates the referred data points for the 14 classes from field campaign and the row represents the classified data by Random Forest.

\begin{tabular}{|c|c|c|c|c|c|c|c|c|c|c|c|c|c|c|c|}
\hline Classified & Artificial & $\begin{array}{c}\text { Bare } \\
\text { Soil }\end{array}$ & Barley & Corn & Wheat & Triticale & Rapeseeds & Oat & $\begin{array}{c}\text { Dense } \\
\text { Grassland }\end{array}$ & Conifer & Deciduous & $\begin{array}{l}\text { Mixed } \\
\text { Forest }\end{array}$ & $\begin{array}{c}\text { Sparse } \\
\text { Grassland }\end{array}$ & Water & Sum \\
\hline Artificial & 156 & 6 & 0 & 9 & 1 & 0 & 0 & 0 & 2 & 0 & 0 & 0 & 1 & 0 & 175 \\
\hline Bare Soil & 5 & 45 & 2 & 4 & 0 & 0 & 0 & 0 & 0 & 0 & 0 & 0 & 0 & 0 & 56 \\
\hline Barley & 0 & 0 & 102 & 20 & 39 & 4 & 7 & 0 & 2 & 0 & 0 & 0 & 6 & 0 & 180 \\
\hline Corn & 4 & 1 & 17 & 310 & 56 & 4 & 5 & 0 & 17 & 0 & 2 & 1 & 12 & 0 & 429 \\
\hline Wheat & 1 & 0 & 30 & 85 & 274 & 15 & 2 & 5 & 21 & 0 & 1 & 0 & 3 & 0 & 437 \\
\hline Triticale & 0 & 0 & 4 & 13 & 31 & 24 & 3 & 1 & 3 & 0 & 0 & 0 & 0 & 0 & 79 \\
\hline Rapeseeds & 0 & 0 & 7 & 6 & 18 & 4 & 33 & 0 & 0 & 0 & 0 & 0 & 1 & 0 & 69 \\
\hline Oat & 0 & 0 & 2 & 2 & 8 & 0 & 0 & 15 & 3 & 0 & 1 & 0 & 0 & 0 & 31 \\
\hline Dense Grassland & 2 & 0 & 2 & 23 & 13 & 0 & 0 & 1 & 674 & 0 & 0 & 0 & 9 & 0 & 724 \\
\hline Conifer & 0 & 0 & 0 & 0 & 1 & 0 & 0 & 0 & 0 & 205 & 0 & 1 & 0 & 0 & 207 \\
\hline Deciduous & 0 & 0 & 0 & 1 & 0 & 0 & 0 & 0 & 1 & 0 & 428 & 7 & 0 & 0 & 437 \\
\hline Mixed Forest & 0 & 0 & 0 & 1 & 0 & 0 & 0 & 0 & 2 & 3 & 19 & 113 & 0 & 0 & 138 \\
\hline $\begin{array}{c}\text { Sparse } \\
\text { Grassland }\end{array}$ & 2 & 0 & 5 & 4 & 14 & 0 & 0 & 0 & 18 & 0 & 0 & 0 & 321 & 0 & 364 \\
\hline Water & 0 & 0 & 0 & 0 & 0 & 0 & 0 & 0 & 0 & 1 & 0 & 0 & 0 & 0 & 1 \\
\hline Sum & 170 & 52 & 171 & 478 & 455 & 51 & 50 & 22 & 743 & 209 & 451 & 122 & 353 & 0 & 3327 \\
\hline
\end{tabular}


Table 5 lists the UA and PA for all the three classification levels considering the best OA value between the $k$-NN and Random Forest algorithm in the classification procedure. For the various land covers among the three levels, forest category is one of the best classified with high PA and UA above 95\%. For instance, the conifer got highest accuracy in Level 2 and Level 3, followed by the deciduous and the mixed forest. At the acquired date of image, the cropland including wheat, barley, rapeseeds, corn and other types show various maturity, i.e. a few corn fields were newly planted whereas several wheat or barley grew mature enough for harvest. Therefore, compared to the classification between cropland and grassland in Level 2, serious misclassification existed in Level 3 category among the different crop fields. The confusion matrix in Table 6 shows the validation data for the 14 classes of Level 3. Because of limited reference pixels from the field campaign, the validation pixels of oat did not exceed the recommended number of 50. Here it was kept for the comparison need. The matrix provides detail information about the mixture of different crops with similar growing characteristics, such as barley and wheat, triticale and wheat. All in all, this single-date Landsat 8 image did not provide sufficient information for distinguishing between detailed croplands, and at least one other image at spring or autumn will be needed to supplement the classification. However, such an (cloudfree) image was not available for this year.

\subsection{Level 1 Classification Based on Time Series of Images (TS1 and TS2)}

Besides the evaluation of the single-date Landsat 8 image, the land cover classification with the time series of images for the Level 1 and Level 2 categories (Figure 5) was carried out via five different variants of spectral bands combination as described in Section 3.1.

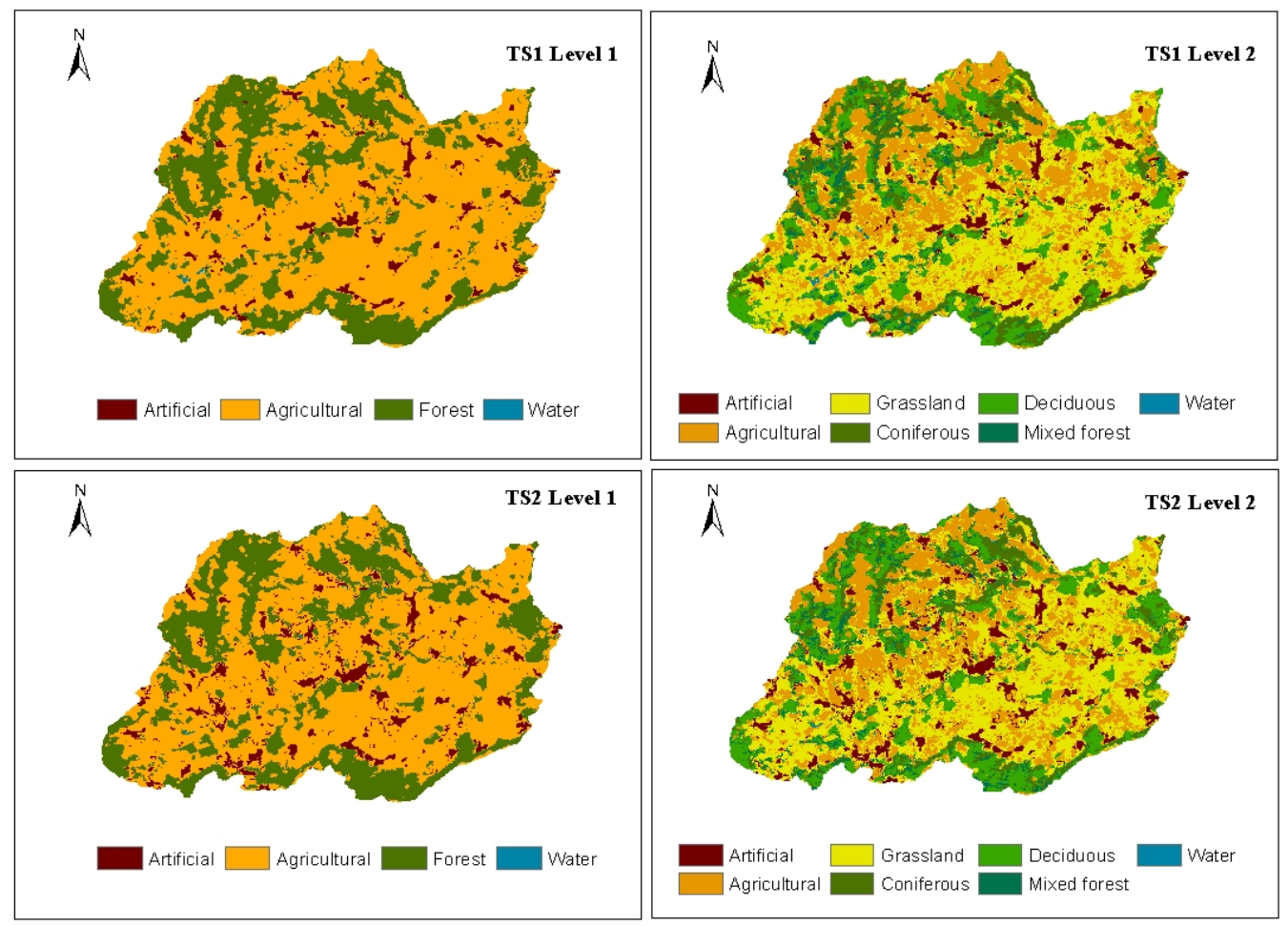

Figure 5. Level 1 and Level 2 land cover maps classified by the k-NN algorithm with time series of thermal images from Landsat 4/5 TM for TS1 and TS2. 
Table 7 lists the OA for the times series TS1 and TS2 images with regard to the Level 1 land cover category by $k$-NN and Random Forest. The accuracy data are given for both classification methods with the image from the earliest time and then successively adding the images up to each time step. As expected, the OA improves with the increase of the images for all the variants. Taking the full set of images in TS1 into account, the B3B4 provides the lowest OA compared to the results of the 3PC, $6 \mathrm{Bands}$ and $7 \mathrm{Bands}$ images. The $\mathrm{OA}$ from $3 \mathrm{PC}$ is very close to the data from the $6 \mathrm{Bands}$ starting from the image number of 4 . The overall accuracies of the thermal images classified by $k$-NN varies greatly in the first three time steps. In comparison, the Random Forest demonstrated more stable performance illustrated in Figure 6. When the image number is greater than 5, the thermal bands began to show their superiority with higher $\mathrm{OA}$ than the $\mathrm{B} 3 \mathrm{~B} 4,3 \mathrm{PC}$ and $6 \mathrm{Bands}$ combination. Both the thermal and the 7 Bands images obtained the best OA of $99.1 \%$ by the $k$-NN algorithm.

Table 7. Overall Accuracy of Level 1 classification by k-NN and Random Forest based on the time series images of the combination of band 3 and band 4 (B3B4), the first three principal components (3PC), the combination of 6 bands (6Bands), the thermal bands and the combination of 7 bands (7Bands).

\begin{tabular}{ccccccccccc}
\hline \multirow{2}{*}{ Image Number } & \multicolumn{2}{c}{ B3B4 (\%) } & \multicolumn{2}{c}{ 3PC (\%) } & \multicolumn{3}{c}{ 6Bands (\%) } & \multicolumn{2}{c}{ Thermal (\%) } & \multicolumn{2}{c}{ 7Bands (\%) } \\
& $\boldsymbol{k}$-NN & RF & $\boldsymbol{k}$-NN & RF & $\boldsymbol{k}$-NN & RF & $\boldsymbol{k}$-NN & RF & $\boldsymbol{k}$-NN & RF \\
\hline TS1-1 & 78.0 & 88.7 & 91.9 & 91.8 & 95.9 & 95.8 & 70.1 & 91.0 & 96.9 & 96.9 \\
TS1-2 & 92.3 & 91.6 & 95.5 & 95.3 & 96.9 & 96.9 & 79.1 & 92.8 & 97.6 & 97.9 \\
TS1-3 & 95.6 & 95.3 & 97.1 & 96.8 & 97.4 & 97.4 & 88.3 & 94.8 & 98.3 & 98.1 \\
TS1-4 & 96.3 & 96.4 & 98.0 & 97.6 & 98.0 & 97.8 & 94.0 & 95.7 & 98.5 & 98.3 \\
TS1-5 & 97.2 & 97.1 & 98.2 & 97.8 & 98.4 & 98.0 & 97.6 & 97.5 & 98.7 & 98.7 \\
TS1-6 & 97.4 & 97.2 & 98.4 & 98.0 & 98.3 & 98.2 & 98.6 & 98.1 & 98.9 & 98.7 \\
TS1-7 & 97.5 & 97.5 & 98.6 & 98.1 & 98.7 & 98.3 & 99.1 & 98.6 & 99.1 & 99.0 \\
\hline TS2-1 & 83.7 & 90.2 & 95.6 & 93.5 & 96.2 & 95.3 & 54.8 & 84.8 & 97.1 & 96.9 \\
TS2-2 & 96.1 & 95.7 & 97.9 & 97.0 & 97.9 & 97.7 & 85.6 & 91.5 & 98.5 & 98.4 \\
TS2-3 & 97.5 & 97.2 & 98.4 & 98.1 & 98.5 & 98.2 & 93.5 & 95.0 & 98.9 & 98.7 \\
TS2-4 & 98.2 & 98.0 & 98.6 & 98.2 & 98.7 & 98.7 & 96.5 & 97.0 & 99.1 & 99.1 \\
TS2-5 & 98.6 & 98.3 & 99.0 & 98.5 & 98.9 & 98.7 & 97.9 & 98.0 & 99.2 & 99.2 \\
TS2-6 & 98.7 & 98.6 & 99.0 & 98.7 & 99.0 & 98.8 & 98.7 & 98.5 & 99.2 & 99.1 \\
\hline
\end{tabular}

The classification results from group TS2 indicate the same tendency that the 3PC and 6Bands show higher OA than the data of the B3B4 and the thermal band. In contrast to the results of group TS1, the thermal images of TS2 with a maximum of six images did not exceed the corresponding results of the 3PC and 6Bands. The thermal band (the right plot in Figure 6) varies when image number is small and the OA increases to the same level as the B3B4 classification at the image number of 6 . From Table 7, it is noteworthy that the time series of 7Bands classification performed by $k$-NN get the best $\mathrm{OA}$ at each time step compared to the other group data. The 3PC images provide nearly similar OA data as the 6Bands when the image number is greater than 3.The best OA among all the data is $99.2 \%$ from the 7 Bands classification calculated by the $k$-NN. The best OA of the thermal images is $98.7 \%$ by $k$-NN and $98.5 \%$ by Random Forest, which is slightly lower than the best OA of 7 Bands. 

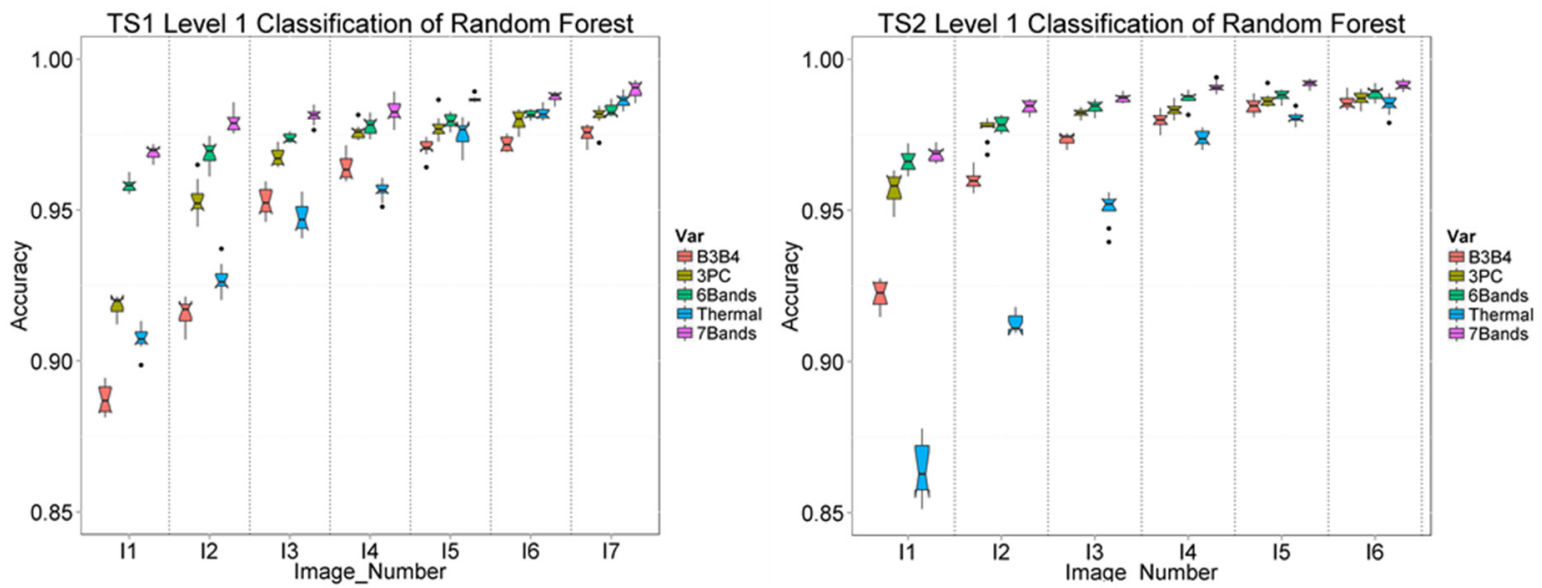

Figure 6. TS1 and TS2 boxplot of the 10-fold Level 1 classification overall accuracy variation by Random Forest for the time series images of the combination of band 3 and band 4 (B3B4), the first three principal components (3PC), the combination of 6 bands (6Bands), the thermal bands and the combination of 7 bands (7Bands).

\subsection{Level 2 Classification Based on Time Series of Images (TS1 and TS2)}

The boxplot in Figure 7 shows the variation of the OA data with regard to the Level 2 land cover classification performed by the Random Forest. Similar to the Level 1 classification, the $k$-NN algorithm has larger variations compared to the Random Forest method when only using the thermal information with an image number smaller than 4 . The OA data by Random Forest varies relatively stable for both TS1 and TS2 data.
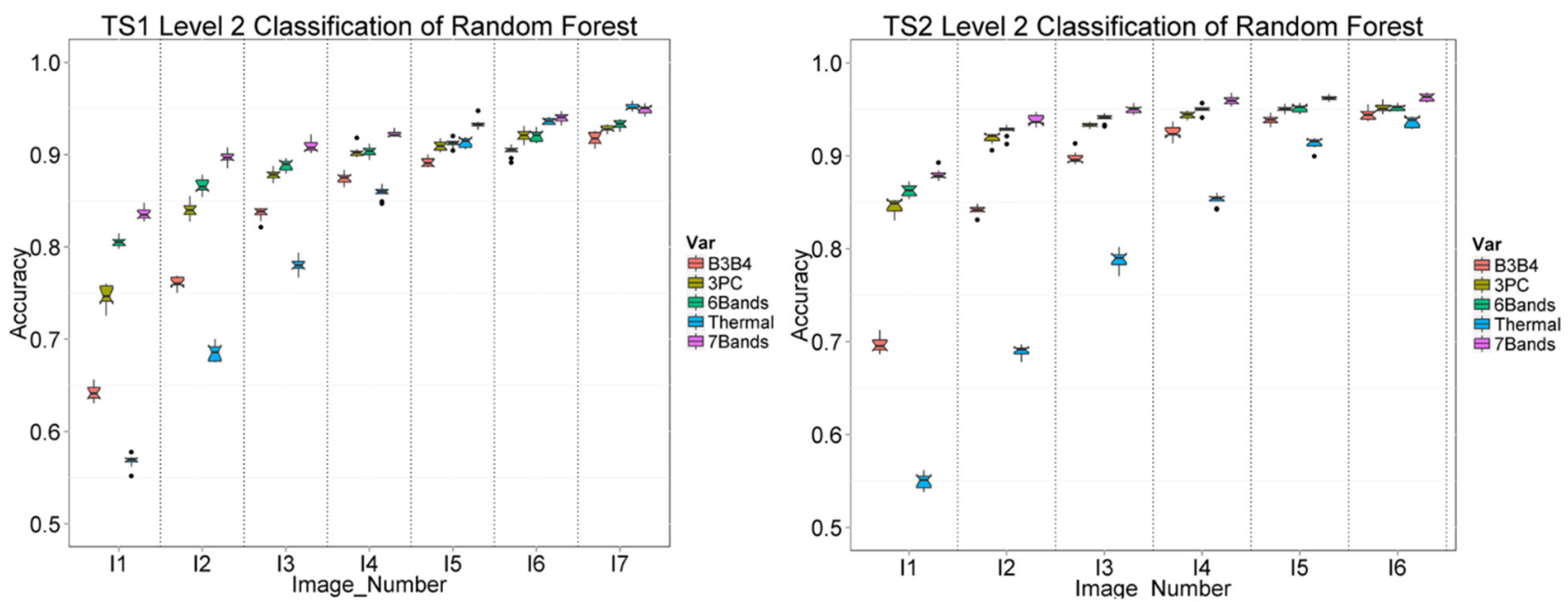

Figure 7. TS1 and TS2 boxplot of the 10-fold Level 2 classification overall accuracy variation by Random Forest for time series images of the combination of band 3 and band 4 (B3B4), the first three principal components (3PC), the combination of 6 bands (6Bands), the thermal bands and the combination of 7 bands (7Bands).

The best OA of TS1 Level 2 classification is $96.6 \%$ achieved by the time series of 7 Bands images (Table 8). The largest OA from the thermal images is obtained by $k-\mathrm{NN}$ as $96.3 \%$, which is about $0.9 \%$ 
to $3.6 \%$ higher than the accuracies of $\mathrm{B} 3 \mathrm{~B} 4,3 \mathrm{PC}$ and $6 \mathrm{Bands}$. Starting from 5 images, the time series of $3 \mathrm{PC}$ and 6Bands in TS1 obtain OA. The classification results using the thermal information by the Random Forest algorithm start to exceed the accuracy of time series of B3B4, 3PC and 6Bands with image number 6 . The bold data in Table 7 and Table 8 imply the best accuracy data among all the OA at each time step. The best OA of $96.9 \%$ from the Level 2 classification results of TS2 (Table 8) comes from the 7Bands image classified by the $k$-NN algorithm, followed by the 6Bands $(96.5 \%)$, 3PC (96.1\%), B3B4 (94.8\%) and the thermal band (93.9\%). In contrast to the TS1 Level 2 classification results, the time series of thermal images obtains the lowest OA at each time step for the TS2. The best value from the thermal band is $93.9 \%$ and the OA starts to exceed $85 \%$ when the images are more than 4. The 3PC and 6Bands also achieve the similar accuracy from four images. The TS2 boxplot in Figure 7 illustrates that the OA increases with the image number for all the time series images, whereas the performance of Level 2 classification based on the TS2 thermal images is not as good as that of the TS1 thermal images.

Table 8. Overall Accuracy of Level 2 classification by $k$-NN and Random Forest based on the time series images of the combination of band 3 and band 4 (B3B4), the first three principal components (3PC), the combination of 6 bands (6Bands), the thermal bands and the combination of 7 bands (7Bands).

\begin{tabular}{ccccccccccc}
\hline \multirow{2}{*}{ Image Number } & \multicolumn{3}{c}{ B3B4 (\%) } & \multicolumn{3}{c}{ 3PC (\%) } & \multicolumn{3}{c}{ 6Bands (\%) } & \multicolumn{2}{c}{ Thermal (\%) } & \multicolumn{2}{c}{ 7Bands (\%) } \\
& $\boldsymbol{k}$-NN & $\mathbf{R F}$ & $\boldsymbol{k}$-NN & $\mathbf{R F}$ & $\boldsymbol{k}$-NN & $\mathbf{R F}$ & $\boldsymbol{k}$-NN & $\mathbf{R F}$ & $\boldsymbol{k}$-NN & $\mathbf{R F}$ \\
\hline TS1-1 & 51.0 & 64.3 & 74.6 & 74.6 & 81.0 & 80.6 & 37.0 & 56.6 & 82.9 & 83.6 \\
TS1-2 & 76.3 & 76.1 & 85.7 & 84.0 & 87.1 & 86.6 & 52.1 & 68.0 & 90.3 & 89.7 \\
TS1-3 & 83.7 & 83.6 & 89.8 & 87.8 & 90.1 & 88.8 & 65.4 & 77.8 & 92.5 & 90.9 \\
TS1-4 & 87.7 & 87.4 & 92.2 & 90.3 & 92.8 & 90.3 & 81.0 & 85.8 & 94.0 & 92.3 \\
TS1-5 & 89.7 & 89.2 & 93.5 & 90.9 & 93.7 & 91.2 & 89.7 & 91.3 & 95.2 & 93.3 \\
TS1-6 & 91.2 & 90.4 & 94.5 & 92.1 & 94.6 & 92.0 & 93.9 & 93.9 & 95.9 & 94.0 \\
TS1-7 & 92.7 & 91.7 & 95.3 & 92.8 & 95.4 & 93.3 & $\mathbf{9 6 . 3}$ & 95.3 & 96.6 & 94.9 \\
\hline TS2-1 & 55.9 & 65.6 & 81.4 & 80.7 & 84.5 & 84.3 & 37.8 & 56.5 & 88.4 & 88.0 \\
TS2-2 & 80.9 & 80.6 & 91.0 & 90.5 & 91.5 & 91.0 & 51.4 & 66.9 & 94.6 & 93.8 \\
TS2-3 & 89.8 & 88.9 & 93.9 & 93.3 & 94.6 & 93.9 & 65.7 & 76.5 & 95.6 & 95.0 \\
TS2-4 & 92.8 & 91.6 & 95.2 & 94.2 & 95.1 & 94.7 & 81.0 & 84.6 & 96.4 & 96.0 \\
TS2-5 & 93.8 & 93.4 & 95.8 & 94.6 & 96.1 & 95.2 & 88.0 & 89.1 & 96.8 & 96.2 \\
TS2-6 & 94.8 & 94.2 & 96.1 & 95.1 & 96.5 & 95.3 & 93.9 & 93.3 & 96.9 & 96.3 \\
\hline
\end{tabular}

The results of Sections 4.1 to 4.3 can be summarized as follows: For the single image classification: (i) Bands4 (97.6\%), Bands6T (98.1\%) and Bands10T (98.3\%) achieved similar OA value of 98\% $\pm 0.4 \%$ for the Level 1 classification; (ii) Bands6T and Bands10T including the two thermal bands got about 5\% and $8 \%$ higher $\mathrm{OA}$ value than that of the Bands4 for the Level 2 classification; (iii) Bands6T and Bands $10 \mathrm{~T}$ obtained $6 \%$ and 12\% higher accuracy than the Bands 4 for the Level 3 classification.

For the Level 1 classification by the time series of images: (i) the thermal images provide comparatively similar OA for both the TS1 and TS2 Level 1 classification, with the best OA of 99.1\% for the TS1 and $98.7 \%$ for the TS2; (ii) When the image number is greater than five, the thermal band shows better OA compared to the B3B4, 3PC and 6Bands for the TS1; (iii) the 7Bands combination 
achieved the best OA at each time step mostly classified by the $k-\mathrm{NN}$, with the OA of $99.1 \%$ for the TS1 and $99.2 \%$ for the TS2; (iv) starting from four images, the 3PC and 6Bands provided comparable accuracy data.

For the Level 2 classification by the time series of images: (i) the best accuracy data of TS1 and TS2 are derived from the 7Bands among all the other images by $k$-NN with the OA of $96.6 \%$ and $96.9 \%$ respectively; (ii) the thermal images get the largest OA at the image number of 6 with $96.3 \%$ for TS1 at the image number of 7, which is higher than B3B4, 3PC and 6Bands; (iii) the TS2 obtained the lowest $\mathrm{OA}$ at each time step compared to the other variants and the best OA of $93.9 \%$ at the image number of 6; (iv) the same feature also exists in the Level 2 classification for the 3PC and 6Bands with the similar accuracy data when the image number is greater than 4 .

\section{Conclusions}

The effectiveness of the thermal information/bands with regard to land cover classification using a single Landsat 8 image (including two thermal bands) and time series of Landsat 4/5 images (including one thermal band) was investigated for the Attert Catchment in Luxemburg. The single image was classified into three levels with 4, 7 and 14 LULC classes, respectively, and the time series of images were classified into the first two levels (Level 3 could not be analyzed due to the lack of ground truth data during the time frame of available images). The $k$-NN and the Random Forest algorithm were applied and assessed within a 10 -fold cross-validation framework.

Firstly, the accuracy results from three variants of the single-date Landsat 8 image indicate that adding the thermal bands has clearly improved the accuracy of the Level 2 and Level 3 classification. The three variants achieved similar high OA of $98 \% \pm 0.4 \%$ for the Level 1 classification. For the Level 2 and Level 3, Bands10T performed well with the best accuracy data, followed by the Bands6T and Bands4, which is $6 \%$ and $12 \%$ higher for the Level 3 classification. The OA from Bands6T including the two thermal bands are 3\% and 6\% higher respectively for the Level 2 and Level 3 category than the data of Bands4 without thermal bands. The results indicate that for the single Landsat 8 image classification, adding the thermal band to the VIR/NIR bands could improve the accuracy by $3 \%$ to $6 \%$ for Level 2 and Level 3 classification. As thermal bands are routinely available from different sensor platforms, their incorporation as input into the classification should also be done on a routine base, thereby significantly increasing classification accuracy.

Secondly, the results from time series of thermal images also demonstrate that the inclusion of thermal band significantly improves the LULC classification, compared to using standard VIS/NIR bands. The classification based on time series of thermal images provided comparably high OA when compared to the B3B4, 3PC, 6Bands and 7Bands images. TS1 thermal images obtained the best OA of 99.1\% for Level 1 classification and $96.3 \%$ for the Level 2 classification. The time series of TS2 thermal images achieved the OA of $98.2 \%$ for the Level 1 and $93.9 \%$ for the Level 2 . It is interesting to observe that the time series of thermal images could provide OA that are as good or even better than using the visible and near-infrared bands in the land cover classification, especially when the combination number of images used is higher than five.

Time series of TS2 thermal images also achieved comparatively high accuracy at the image number of 6 , although the value is not higher than other images. Based on our results, a time-series of at least 5 
or 6 thermal images is recommended as being almost optimal for situations that are similar to our study area. If the images from different years are obtained in the area with varying land cover and land use, the classification catalog and the selection of training set should be paid more attention with more land cover catalogs or taking the land cover change as the new class to ensure the consistence of the images in different years. In this study, the cloud free Landsat images were received mainly in the spring and summer time. They demonstrate the temperature discrepancies between various types of land cover especially for the agriculture areas, which is very effective for the Level 2 classification with the high OA from $93.9 \%$ to $96.3 \%$. For the classification with the time series of images in the same year, at least two images from spring or summer time are recommended as the complementary sources.

Our study is not aimed at replacing the existing profound classification methods, but trying to add the thermal bands to improve the land cover classification based on the single image or the time series of images. The incorporation of thermal information improved the land cover classification indicated by better OA and Kappa statistics. However, in addition, thermal information alone provides similar or even better results when compared to the other time series of visible and near-infrared bands combination and/or principal components. Therefore, in case of failures or non-availability of VIS/NIR band data (as has been the case e.g. for the ASTER NIR bands), the thermal information could serve as a good substitute input in land cover classification experiments.

So far, the study area is limited to the Attert catchment in Luxembourg and the detailed land cover catalog is only classified at Level 2 (seven classes) when using time series of images, due to the lack of images in the same year for the agricultural area and therefore missing ground truth information. Because of the complicated atmosphere conditions, the preprocessing of the time series images probably could further benefit from other novel correction procedures, such as relative radiometric normalization [50]. Further investigation of the time series of thermal remote sensing will be extended to the more specific classification for higher level with more specific land covers (such as Level 3 CORINE classes and/or application in agricultural and hydrological land cover types). The thermal bands in Landsat satellites have the limitation of a coarser spatial resolution when compared to the VIS/NIR bands, but the developed data fusion methods (such as e.g. the wavelet fusion method [64] or the Spatial and Temporal Adaptive Reflectance Fusion Model (STARFM) [65,66]). Other thermal sensors with wider spectral range such as ASTER or the sensor installed on the drone with finer spatial resolution and hyperspectral data [67] should also be explored to aggregate the information for the regional land cover classification, but this is subject of ongoing and future research.

\section{Acknowledgments}

The authors would like to sincerely thank the German Research Foundation (DFG) for funding this research through the CAOS (Catchments as Organized Systems) Research Unit (FOR 1598, SCHU1271/5-1), and the China Scholarship Committee for the support of the research and USGS for providing all the Landsat images. The authors are also grateful to Christina Elisabeth Thiem and Thomas Weiß for the great help in the field campaign. The authors also wish to thank all the reviewers for their valuable comments and suggestions. 


\section{Author Contributions}

This research idea was conceived by Karsten Schulz. The experiments were designed and performed by Liya Sun. The data was analyzed and interpreted by Liya Sun and Karsten Schulz. The manuscript was wrote by Liya Sun and revised by Karsten Schulz.

\section{Conflicts of Interest}

The authors declare no conflict of interest.

\section{References}

1. Anderson, G. Encyclopedia of Hydrological Sciences; Wiley: New York, NY, USA, 2005.

2. Liang, S. Advances in Land Remote Sensing: System, Modeling, Inversion and Application; Springer: Berlin, Heidelberg, Germany, 2008.

3. Bounoua, L.; DeFries, R.; Collatz, G.J.; Sellers, P.; Khan, H. Effects of land cover conversion on surface climate. Climatic Change 2002, 52, 29-64.

4. Dickinson, R.E. Land processes in climate models. Remote Sens. Environ. 1995, 51, 27-38.

5. Nilsson, C.; Pizzuto, J.E.; Moglen, G.E.; Palmer, M.A.; Stanley, E.H.; Bockstael, N.E.; Thompson, L.C. Ecological forecasting and the urbanization of stream ecosystems: Challenges for economists, hydrologists, geomorphologists, and ecologists. Ecosystems 2003, 6, 659-674.

6. Sexton, J.O.; Urban, D.L.; Donohue, M.J.; Song, C. Long-term land cover dynamics by multi-temporal classification across the Landsat-5 record. Remote Sens. Environ. 2013, $128,246-258$.

7. Samaniego, L.; Schulz, K. Supervised classification of agricultural land cover using a modified k-NN technique (MNN) and landsat remote sensing imagery. Remote Sens. 2009, 1, 875-895.

8. Salovaara, K.J.; Thessler, S.; Malik, R.N.; Tuomisto, H. Classification of Amazonian primary rain forest vegetation using Landsat ETM+ satellite imagery. Remote Sens. Environ. 2005, 97, 39-51.

9. Lu, D.; Weng, Q. Use of impervious surface in urban land-use classification. Remote Sens. Environ. 2006, 102, 146-160.

10. Sobrino, J.A.; Raissouni, N. Toward remote sensing methods for land cover dynamic monitoring: Application to morocco. Int. J. Remote Sens. 2000, 21, 353-366.

11. Gong, P.; Wang, J.; Yu, L.; Zhao, Y.; Zhao, Y.; Liang, L.; Niu, Z.; Huang, X.; Fu, H.; Liu, S.; et al. Finer resolution observation and monitoring of global land cover: First mapping results with Landsat TM and ETM+ data. Int. J. Remote Sens. 2012, 34, 2607-2654.

12. Crocetto, N.; Tarantino, E. A class-oriented strategy for features extraction from multidate ASTER imagery. Remote Sens. 2009, 1, 1171-1189.

13. Jianwen, M.; Bagan, H. Land-use classification using ASTER data and self-organized neutral networks. Int. J. Appl. Earth Obs. Geoinf. 2005, 7, 183-188.

14. Zhu, G.; Blumberg, D.G. Classification using ASTER data and SVM algorithms: The case study of Beer Sheva, Israel. Remote Sens. Environ. 2002, 80, 233-240.

15. Marçal, A.R.S.; Borges, J.S.; Gomes, J.A.; Pinto Da Costa, J.F. Land cover update by supervised classification of segmented ASTER images. Int. J. Remote Sens. 2005, 26, 1347-1362. 
16. French, A.N.; Schmugge, T.J.; Ritchie, J.C.; Hsu, A.; Jacob, F.; Ogawa, K. Detecting land cover change at the Jornada Experimental Range, New Mexico with ASTER emissivities. Remote Sens. Environ. 2008, 112, 1730-1748.

17. Lunetta, R.S.; Balogh, M.E. Application of multi-temporal Landsat 5 TM imagery for wetland identification. Photogramm. Eng. Remote Sens. 1999, 65, 1303-1310.

18. Murai, H.; Omatu, S. Remote sensing image analysis using a neural network and knowledge-based processing. Int. J. Remote Sens. 1997, 18, 811-828.

19. Maxwell, S.K.; Nuckols, J.R.; Ward, M.H.; Hoffer, R.M. An automated approach to mapping corn from Landsat imagery. Comput. Electron. Agric. 2004, 43, 43-54.

20. Langley, S.K.; Cheshire, H.M.; Humes, K.S. A comparison of single date and multitemporal satellite image classifications in a semi-arid grassland. J. Arid. Environ. 2001, 49, 401-411.

21. Saadat, H.; Adamowski, J.; Bonnell, R.; Sharifi, F.; Namdar, M.; Ale-Ebrahim, S. Land use and land cover classification over a large area in Iran based on single date analysis of satellite imagery. ISPRS J. Photogramm. Remote Sens. 2011, 66, 608-619.

22. Guerschman, J.P.; Paruelo, J.M.; Bella, C.D.; Giallorenzi, M.C.; Pacin, F. Land cover classification in the Argentine Pampas using multi-temporal Landsat TM data. Int. J. Remote Sens. 2003, 24, 3381-3402.

23. Yuan, F.; Sawaya, K.E.; Loeffelholz, B.C.; Bauer, M.E. Land cover classification and change analysis of the Twin Cities (Minnesota) Metropolitan Area by multitemporal Landsat remote sensing. Remote. Sens. Environ. 2005, 98, 317-328.

24. Wilson, E.H.; Sader, S.A. Detection of forest harvest type using multiple dates of Landsat TM imagery. Remote. Sens. Environ. 2002, 80, 385-396.

25. Brown, J.C.; Kastens, J.H.; Coutinho, A.C.; de Castro Victoria. D.; Bishop, C.R. Classifying multiyear agricultural land use data from Mato Grosso using time-series MODIS vegetation index data. Remote Sens. Environ. 2013, 130, 39-50.

26. Carrão, H.; Gonçalves, P.; Caetano, M. Contribution of multispectral and multitemporal information from MODIS images to land cover classification. Remote Sens. Environ. 2008, 112, 986-997.

27. Ozdogan, M.; Gutman, G. A new methodology to map irrigated areas using multi-temporal MODIS and ancillary data: An application example in the continental US. Remote Sens. Environ. 2008, 112, 3520-3537.

28. Collins, M.J.; Dymond, C.; Johnson, E.A. Mapping subalpine forest types using networks of nearest neighbour classifiers. Int. J. Remote Sens. 2004, 25, 1701-1721.

29. Samaniego, L.; Bardossy, A.; Schulz, K., Supervised classification of remotely sensed imagery using a modified k-NN technique. IEEE Trans. Geosci. Remote. Sens. 2008, 46, 2112-2125.

30. Gislason, P.O.; Benediktsson, J.A.; Sveinsson, J.R. Random forests for land cover classification. Pattern Recognit. Lett. 2006, 27, 294-300.

31. Deng, C.; Wu, C. The use of single-date MODIS imagery for estimating large-scale urban impervious surface fraction with spectral mixture analysis and machine learning techniques. ISPRS J. Photogramm. Remote Sens. 2013, 86, 100-110. 
32. Corcoran, J.; Knight, J.; Gallant, A. Influence of multi-source and multi-temporal remotely sensed and ancillary data on the accuracy of random forest classification of wetlands in Northern Minnesota. Remote Sens. 2013, 5, 3212-3238.

33. Lucas, R.; Rowlands, A.; Brown, A.; Keyworth, S.; Bunting, P. Rule-based classification of multi-temporal satellite imagery for habitat and agricultural land cover mapping. ISPRS J. Photogramm. Remote Sens. 2007, 62, 165-185.

34. Rodriguez-Galiano, V.F.; Chica-Olmo, M.; Abarca-Hernandez, F.; Atkinson, P.M.; Jeganathan, C. Random Forest classification of mediterranean land cover using multi-seasonal imagery and multi-seasonal texture. Remote Sens. Environ. 2012, 121, 93-107.

35. Southworth, J. An assessment of Landsat TM band 6 thermal data for analysing land cover in tropical dry forest regions. Int. J. Remote Sens. 2004, 25, 689-706.

36. Li, Z.L.; Tang, B.H.; Wu, H.; Ren, H.; Yan, G.; Wan, Z.; Trigo, I.F.; Sobrino, J.A. Satellite-derived land surface temperature: Current status and perspectives. Remote Sens. Environ. 2013, 131, 14-37.

37. Liu, L.; Zhang, Y. Urban heat island analysis using the Landsat TM data and ASTER data: A case study in Hong Kong. Remote Sens. 2011, 3, 1535-1552.

38. Su, Z., The Surface Energy Balance System (SEBS) for estimation of turbulent heat fluxes. Hydrol. Earth Syst. Sci. 2002, 6, 85-100.

39. Kogan, F.N. Operational space technology for global vegetation assessment. Bull. Am. Meteorol. Soc. 2001, 82, 1949-1964.

40. Kustas, W.; Anderson, M. Advances in thermal infrared remote sensing for land surface modeling. Agric. Meteorol. 2009, 149, 2071-2081.

41. Foody, G.M. Approaches for the production and evaluation of fuzzy land cover classifications from remotely-sensed data. Int. J. Remote Sens. 1996, 17, 1317-1340.

42. Defries, R.S.; Hansen, M.C.; Townshend, J.R.G. Global continuous fields of vegetation characteristics: A linear mixture model applied to multi-year $8 \mathrm{~km} \mathrm{AVHRR} \mathrm{data.} \mathrm{Int.} \mathrm{J.} \mathrm{Remote}$ Sens. 2000, 21, 1389-1414.

43. Cover, T.M.; Hart, P.E. Nearest neighbor pattern classification. IEEE Trans Inf. Theory. 1967, 13, 21-27.

44. Breiman, L. Random forests. Mach. Learn. 2001, 45, 5-32.

45. EEA Corine Land Cover. Available online: http://www.eea.europa.eu/publications/COR0-landcover (accessed on 01 July 2012).

46. Foody, G.M.; Mathur, A.; Sanchez-Hernandez, C.; Boyd, D.S. Training set size requirements for the classification of a specific class. Remote Sens. Environ. 2006, 104, 1-14.

47. Mather, P.; Koch, M. Computer Processing of Remotely-Sensed Images: An Introduction; Wiley: New York, NY, USA, 2010.

48. Song, C.; Woodcock, C.E.; Seto, K.C.; Lenney, M.P.; Macomber, S.A. Classification and change detection using Landsat TM data: When and how to correct atmospheric effects? Remote Sens. Environ. 2001, 75, 230-244.

49. Lu, D.; Weng, Q. A survey of image classification methods and techniques for improving classification performance. Int. J. Remote Sens. 2007, 28, 823-870. 
50. Vicente-Serrano, S.M.; Pérez-Cabello, F.; Lasanta, T. Assessment of radiometric correction techniques in analyzing vegetation variability and change using time series of Landsat images. Remote Sens. Environ. 2008, 112, 3916-3934.

51. Berk, A.; Bernstein, L.S.; Anderson, G.P.; Acharya, P.K.; Robertson, D.C.; Chetwynd, J.H.; Adler-Golden, S.M. MODTRAN cloud and multiple scattering upgrades with application to AVIRIS. Remote Sens. Environ. 1998, 65, 367-375.

52. Atcor for Imagine: Downloads. Available online: http:/www.geosystems.de/atcor/downloads/ index.html (accessed on 20 August 2013).

53. Real-Time Product Documentation. Available online: http://www.hexagongeospatial.com/ resources/documentation (accessed on 1 June 2013).

54. ASTER Global Digital Elevation Map Announcement. Available online: http://asterweb.jpl.nasa.gov/gdem.asp (access on 17 July 2013).

55. Singh, A. Review article digital change detection techniques using remotely-sensed data. Int. J. Remote Sens. 1989, 10, 989-1003.

56. Almeida-Filho, R.; Shimabukuro, Y.E. Digital processing of a Landsat-TM time series for mapping and monitoring degraded areas caused by independent gold miners, Roraima State, Brazilian Amazon. Remote Sens. Environ. 2002, 79, 42-50.

57. Li, C.; Wang, J.; Wang, L.; Hu, L.; Gong, P. Comparison of classification algorithms and training sample sizes in urban land classification with Landsat thematic mapper imagery. Remote Sens. 2014, 6, 964-983.

58. Richards, J.A.; Jia, X. Remote Sensing Digital Image Analysis: An Introduction; Springer: Berlin/Heidelberg, Germany, 2006.

59. Rodriguez-Galiano, V.F.; Ghimire, B.; Rogan, J.; Chica-Olmo, M.; Rigol-Sanchez, J.P. An assessment of the effectiveness of a random forest classifier for land-cover classification. ISPRS J. Photogramm. Remote Sens. 2012, 67, 93-104.

60. Kohavi, R. A study of cross-validation and bootstrap for accuracy estimation and model selection. In Proceedings of the 14th International Joint Conference on Artificial Intelligence, Montreal, QC, Canada, 20-25 August 1995.

61. Congalton, R.G. A review of assessing the accuracy of classifications of remotely sensed data. Remote Sens. Environ. 1991, 37, 35-46.

62. Congalton, R.G.; Green, K. Assessing the Accuracy of Remotely Sensed Data: Principles and Practices; CRC Press: Boca Raton, FL, USA, 2009.

63. Anderson, J.R. A Land Use and Land Cover Classification System for Use with Remote Sensor Data; U.S. Government Printing Office: Washington, DC, USA, 1976.

64. Bagan, H.; Ma, J.; Li, Q.; Liu, Z.; Han, X. Use of wavelet high-frequency substitution fusion to increase remote sensing image spatial resolution. In Proceedings of 3rd International Symposium on Multispectral Image Processing and Pattern Recognition, Beijing, China, 20 October 2003.

65. Feng, G.; Masek, J.; Schwaller, M.; Hall, F. On the blending of the Landsat and MODIS surface reflectance: Predicting daily Landsat surface reflectance. IEEE Trans. Geosci. Remote Sens. 2006, 44, 2207-2218. 
66. Zhu, X.; Chen, J.; Gao, F.; Chen, X.; Masek, J.G. An enhanced spatial and temporal adaptive reflectance fusion model for complex heterogeneous regions. Remote Sens. Environ. 2010, 114, 2610-2623.

67. Segl, K.; Roessner, S.; Heiden, U.; Kaufmann, H. Fusion of spectral and shape features for identification of urban surface cover types using reflective and thermal hyperspectral data. ISPRS J. Photogramm. Remote Sens. 2003, 58, 99-112.

(C) 2015 by the authors; licensee MDPI, Basel, Switzerland. This article is an open access article distributed under the terms and conditions of the Creative Commons Attribution license (http://creativecommons.org/licenses/by/3.0/). 